American Journal of Environmental Sciences 7 (6): 499-504, 2011

ISSN 1553-345X

(C) 2011 Science Publications

\title{
Particulate Matter in the Excavation Work Sites in Urban Areas
}

\author{
Giuseppe Pizzo and Marina Clerico \\ Department of Environment and Geo-Engineering, \\ Politecnico di Torino, Faculty of Environmental Engineering, \\ Corso Duca degli Abruzzi 24, 10129 Torino, Italy
}

\begin{abstract}
Problem statement: Excavation work sites in urban areas for infrastructures and buildings cause a great deal of disturbance and damage due to the emission of particulate matter, in particular in the area involved in urban renovation work. Under Italian legislation limits currently exist for $\mathrm{PM}_{10}$ and PM2, 5 but, in the case of excavation work sites, it would be also necessary to consider limits for Total Suspended Particulate Matter (TSP), but these no longer exist. Approach: A 20-month monitoring period near the exposed population was carried out measuring and analyzing the concentration of TSP, $\mathrm{PM}_{10}$ and PM2, 5. This monitoring was done in order to determine statistically significant results, to find out what the pollutant sources are and the microclimate conditions and the particle-size values to take into account as a critical condition to be managed and controlled inside excavation work sites in an urban area. Results: The data obtained shows that excavation work sites increase particulate matter concentration, which may already be high. $\mathrm{PM}_{10}$ measured near the excavation work site and urban traffic, represented about $70 \%$ of TSP. In the city measurement of $\mathrm{PM}_{10}$ were usually around $10 \%$ higher. TSP concentration values depended on the type of work activity and, although they were similar to TSP concentration values in the city, sometimes they were $60 \%$ higher. Conclusion: The high levels of particulate matter due to the excavation work sites in urban areas can significantly increase the health risk effect. In the roads near the excavation work sites, even when there is no excavation work activity, the resurgence of dust from the ground by vehicles results in high levels of TSP. The results of this study are of interest for local government as a basis for prevention, monitoring and control of environmental impacts due to the dispersion of dust into the atmosphere, generated by excavation work sites.
\end{abstract}

Key words: Total Suspended Particulate Matter (TSP), local government, excavation work sites, environmental impacts, imposing limit, quality standards

\section{INTRODUCTION}

The interest on health problem concerning the exposure to particulate matter, has focalized, in the last decades (APHEIS, 2005), the attention on specific particle size (EPA, 2005) and on the improvement of sampling (Tsai and Huang, 1995) methods EPA, 2006.

Since 1980 the EU has been approving several directives on air quality, in particular to manage and control great industrial plants (EEA, 2007), by imposing limit values for pollutants.

Directive 96/62/CE on the Evaluation and management of air quality in the environment is aimed at protecting human health and the environment with harmonized European procedures.
Directive 99/30/CE establishes air quality limit values for different pollutants. $\mathrm{PM}_{10}$ is limited to $50 \mu \mathrm{g}$ $\mathrm{m}^{-3}$ on $24 \mathrm{~h}$ and to $20 \mu \mathrm{g} \mathrm{m}^{-3}$ averages per year.

The Sixth Environment Action Programme entitled "Environment 2010: Our Future, Our Choice", which covers the period from 22 July 2002 to 21 July 2012, introduces limit values for $\mathrm{PM}_{10}$ and $\mathrm{PM} 2,5$, ensuring the application of air quality standards (WHO, 2005; AQEG, 2005; EEA, 1999) and defining a strategy on air pollution.

In Italy the evolution of monitoring, according to UE Directives, starts from TSP sampling (19942002) to $\mathrm{PM}_{10}$ (from 2002) (Paoletti et al., 2002) and PM2, 5 (from 2010).

In the excavation work sites, due to particular particle size of the work activity of crushing, demolition, 
excavation and grading land, it would be necessary to consider, besides $\mathrm{PM}_{10}$ and PM2, 5, also TSP.

Since in Italy the legislation does no longer take into account TSP, the $150 \mu \mathrm{m} \mathrm{m}^{-3}$ attention limit value and the $300 \mu \mathrm{m} \mathrm{m}^{-3}$ warning value of the repealed law, could be used to safeguard the human health.

This study is aimed, through a 20-month monitoring period of TSP, $\mathrm{PM}_{10}$ and $\mathrm{PM} 2,5$ in an important excavation work site, at understanding the real contribute to the particulate matter of the work activity, in order to know which the parameter to consider safeguarding the exposed population are.

Several literature studies (ATS, 2000; Dockery et al., 1993; 1996; Hester and Harrison, 1998) on the effects of particular matter show the correlation between dust concentration and the manifestation of chronic respiratory diseases (asthma, bronchitis, emphysema) and cardiovascular diseases. Larger particle size induce irritation, dryness and inflammation of larynx and pharynx, while smaller particle size (less than 5-6 $\mu \mathrm{m}$ ) can cause and aggravate chronic respiratory diseases (asthma, bronchitis, emphysema), induce bronchial inflammation, fibrosis, ischemia, tumor and in general reduce the immune system versus infections and other pollutants (WHO, 2003).

This study wants to evaluate the criticity of the excavation work sites, through the correlation between TSP, $\mathrm{PM}_{10}$ and PM2, 5 considering the meteorological, traffic and type of sources effects.

\section{MATERIALS AND METHODS}

The measurement method used for the sampling of TSP, $\mathrm{PM}_{10}$ and PM2, 5 is gravimetric, using the filter weight difference before and after sampling.

The filter used is fiber quartz, diameter $47 \mathrm{~mm}$, sampling efficiency $>99.5 \%$, according to standard EN 12341:2001.

The analytical balance has a sensitivity of $0.01 \mathrm{mg}$.

The instruments used for sampling are Fig. 1:

- Sequential Sampler EXPLORER PLUS CONTROLLER 16 (16 filters)

- $\quad$ Sequential Solenoid Sampler EXPLORER EV8 (8 filters)

Using the pickup heads according to UNI EN $12341\left(2.3 \mathrm{~m}^{-3} \mathrm{~h}\right)$, the sequential system complies with the requirements of current legislation.

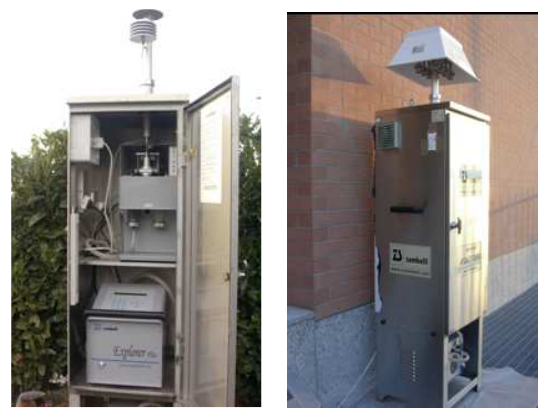

Fig. 1: Sequential Sampler EXPLORER PLUS CONTROLLER 16 (16 filters) and Sequential Solenoid Sampler EXPLORER EV8 (8 filters)

The instrument is equipped with sensors for the detection of micro-climatic conditions (temperature, pressure, humidity).

Using the appropriate sampling head, it was possible to sample TSP, $\mathrm{PM}_{10}$ and PM2, 5 .

Case study: The case study is about the analysis of the airborne dust generated by a large excavation work site in urban area, which belongs to an important project to transform the city.

The site occupies an area of about $135,000 \mathrm{~m}^{-2}$. The area involves a large residential area and the construction of shopping malls and expansion of green areas, in order to make this new urban order a new pole of attraction of the city.

The interventions provided within the site, which represent a source of dust, are divided into the following activities:

- Demolition of the buried artifacts structures and foundations of existing industrial sites

- Crushing and screening of debris from demolition in mobile plant for the recovery of non-hazardous waste, installed within the site area. This material is deposited in specific areas waiting for the re-use within the site or marketed outside

- Excavations for infrastructure works and private construction. The material is loaded onto trucks and delivered to the screening plant located within the area. The undersize fraction is deposited in the appropriate areas in heaps of $1000 \mathrm{~m}^{3}$. This material is dampened (by watering) or covered with protective HDPE sheeting to prevent dispersion of dust into the atmosphere

- Backfill material from undersize, by grab excavators, loaders and graders

The typical sources of dust emission in the excavation work sites are: 
- Tracks yard and storage areas

- Areas of material handling

- The resurgence by wind

Another important emission, unless properly controlled, is the transportation of materials on public roads; because of the dispersion of the load and the release of the means of transport not enough cleaned (tires, boxes).

It is also important to assess the contribution of road traffic emissions. The dispersion of dust into the air also depends on weather conditions.

Monitoring of particulate matter: The first Point (P1) of monitoring Fig. 2 is located near a residential building with 160 families in the entire complex and about 70 families in the side directly exposed to the site. This building, considered as a critical point, is located a few meters away from the site, near an urban traffic road.

During most of the measurement period, the site area, next to the monitoring point, was characterized by the presence of high mounds of variable size material, located a few meter from the building complex, which have affected the data collected.

The second monitoring Point (P2) is located near a residential complex Fig. 3 in which 150 families live, half of them directly exposed to the site. The site is 15$30 \mathrm{~m}$ from the facade of the buildings and P2 is about $200 \mathrm{~m}$ far from the urban traffic road.

The working cycle runs from Monday to Friday from 9 a.m. to 18 p.m. and on Saturdays from 9 a.m. to 13 p.m.

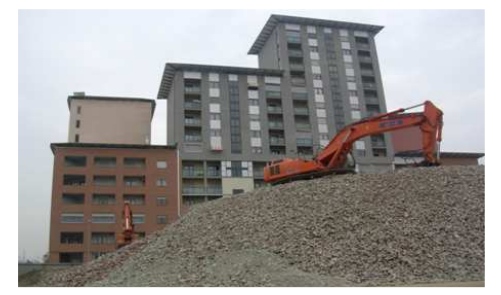

Fig. 2: First monitoring Point (P1)

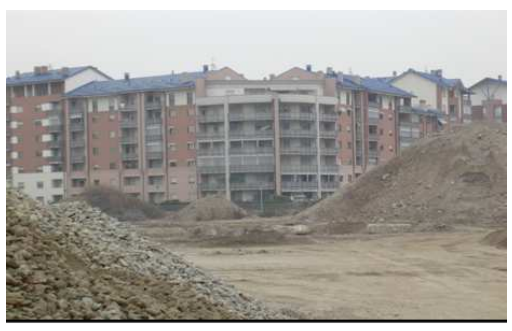

Fig. 3: Second monitoring Point (P2)
The monitoring took place over $24 \mathrm{~h}$ for a total duration of $20 \mathrm{~m}$.

The obtained values were compared with the values of the law, in particular:

- TSP-Level of attention: $150 \mu \mathrm{g} \mathrm{m}^{-3}$; Alert level: $300 \mu \mathrm{g} \mathrm{m}^{-3}$

- $\mathrm{PM}_{10}-24 \mathrm{~h}$ limit value: $50 \mu \mathrm{g} \mathrm{m}^{-3}$ not to be exceeded more than 35 times per year

- $\quad \mathrm{PM} 2,5: 25 \mu \mathrm{g} \mathrm{m}^{-3}$

The monitoring results were compared with the values of the measuring stations located throughout the city, in order to better understand the contribution of the excavation work site and the traffic pollution.

\section{RESULTS}

The TSP results of January measurement in P1, reported in Table 1, have been related to the meteorological condition and to the activity of the excavation work site.

The TSP results of January measurement in P1 are reported as example in Table 2.

Table 3 and Fig. 4 show the concentration in the two monitoring point P1 and P2 in comparison with measurements from a monitoring station in the city, not so far from the site, referring to the same period of analysis. This is aimed at evaluating the origin and composition of the TSP.

Table 1: Correlation results-meteo condition-type of work activities in January

\begin{tabular}{lllc} 
& Monitoring data:TSP-Month; January- Location: P1 \\
& Meteo & type of & conc. TSP \\
\hline Day/month & condition & work activity $\left(^{*}\right)$ & $\left(\mu \mathrm{g} \mathrm{m}^{-3}\right)$ \\
$01 / 01$ & Cloud & NO ACTIVITY & 162,2 \\
$02 / 01$ & Cloud & CM & 130,1 \\
$03 / 01$ & Rain & CM & 37,2 \\
$04 / 01$ & Rain & CM & 30,8 \\
$05 / 01$ & Cloud & CM & 38,4 \\
$06 / 01$ & Rain & CM & 33,9 \\
$07 / 01$ & Sun & CM & 90,8 \\
$08 / 01$ & Cloud & D & 81,1 \\
$09 / 01$ & Cloud & D & 82,3 \\
$10 / 01$ & Sun & S D CM & 165,8 \\
$11 / 01$ & Sun & NO ACTIVITY & 108,6 \\
$14 / 01$ & Cloud & S & n.a. \\
$15 / 01$ & Cloud & S & 20,7 \\
$16 / 01$ & Rain & S & 19,6 \\
$18 / 01$ & Sun & SFD & 124,1 \\
$21 / 01$ & Fog/ Cloud & CM & 155,5 \\
$22 / 01$ & Sun & CM & 172,9 \\
$28 / 01$ & Sun & SFD & 137,9 \\
$29 / 01$ & Sun & SCM & n.a. \\
$30 / 01$ & Cloud & SCM & 137,2 \\
$31 / 01$ & Cloud & CM & 179,8 \\
\hline & & &
\end{tabular}


Am. J. Environ. Sci., 7 (6): 499-504, 2011

Table 2: TSP results in P1 in January

\begin{tabular}{|c|c|c|c|c|c|c|c|}
\hline \multirow[b]{2}{*}{ Day/month } & \multirow[b]{2}{*}{ Average $\left({ }^{\circ} \mathrm{C}\right)$} & \multicolumn{6}{|c|}{ Monitoring data: TSP - Month; January - Location: P1 } \\
\hline & & $\begin{array}{l}\text { Average } \mathrm{p} \\
(\mathrm{hPa})\end{array}$ & $\begin{array}{l}\text { Average } \\
\text { humidity (\%) }\end{array}$ & $\begin{array}{l}\text { Duration } \\
(\mathrm{min})\end{array}$ & $\begin{array}{l}\text { Volume } \\
\text { (Litres) }\end{array}$ & $\begin{array}{l}\text { TSP wheight } \\
(\mu \mathrm{g})\end{array}$ & $\begin{array}{l}\text { Conc. TSP } \\
\left(\mu \mathrm{g} \mathrm{m}^{-3}\right)\end{array}$ \\
\hline$\overline{01 / 01}$ & 5,3 & 1045,9 & 49,71 & 1440 & 50618,8 & 8210 & 162,2 \\
\hline $02 / 01$ & 5,1 & 1045,1 & 62,47 & 1440 & 51352,6 & 6680 & 130,1 \\
\hline 03/01 & 4,5 & 1043,6 & 74,01 & 1440 & 51103,9 & 1900 & 37,20 \\
\hline $04 / 01$ & 6,3 & 1046,6 & 79,45 & 1440 & 51301,6 & 1580 & 30,80 \\
\hline 05/01 & 8,0 & 1041 & 81,58 & 1440 & 51327,2 & 1970 & 38,40 \\
\hline $06 / 01$ & 8,2 & 1039,2 & 77,45 & 1440 & 51870,1 & 1760 & 33,90 \\
\hline $07 / 01$ & 6,9 & 1043,4 & 77,98 & 1440 & 33596,1 & 3050 & 90,80 \\
\hline 08/01 & 6,4 & 1049,9 & 79,62 & 1440 & 51673,5 & 4190 & 81,10 \\
\hline $09 / 01$ & 7,5 & 1048,4 & 74,61 & 1440 & 51381,6 & 4230 & 82,30 \\
\hline $10 / 01$ & 7,6 & 1048,9 & 68,33 & 1440 & 51199,1 & 8490 & 165,8 \\
\hline $11 / 01$ & 7,5 & 1044,1 & 74,26 & 1440 & 50842,1 & 5520 & 108,6 \\
\hline $14 / 01$ & 9,4 & 1041,6 & 75,52 & 1440 & 50427,6 & n.a. & n.a. \\
\hline $15 / 01$ & 9,1 & 1040,1 & 79,73 & 1440 & 51165,6 & 1060 & 20,70 \\
\hline $16 / 01$ & 8,8 & 1032,7 & 81,57 & 1440 & 51499,4 & 1010 & 19,60 \\
\hline $18 / 01$ & 9,8 & 1041,7 & 63,1 & 1440 & 50376,2 & 6250 & 124,1 \\
\hline $21 / 01$ & 7,4 & 1043,6 & 80,35 & 1440 & 49139,1 & 7640 & 155,5 \\
\hline $22 / 01$ & 11,3 & 1033,9 & 52,6 & 1440 & 49162,9 & 8500 & 172,9 \\
\hline $28 / 01$ & 14,8 & 1044,9 & 41,84 & 1440 & 50094,1 & 6910 & 137,9 \\
\hline $29 / 01$ & 11,1 & 1048,1 & 64,88 & 1440 & 49441,3 & n.a. & n.a. \\
\hline $30 / 01$ & 10,4 & 1042,9 & 72,57 & 1440 & 49764,7 & 6830 & 137,2 \\
\hline $31 / 01$ & 9,9 & 1040,1 & 70,7 & 1440 & 48997,7 & 8810 & 179,8 \\
\hline
\end{tabular}

Table 3: TSP concentration in P1, P2 and comparison with a monitoring station in the city

\begin{tabular}{lccc}
\hline & $\begin{array}{c}\text { Conc. TSP } \\
\text { in P1 } \\
\left(\mu \mathrm{g} \mathrm{m}^{-3}\right)\end{array}$ & $\begin{array}{l}\text { Conc. TSP } \\
\text { in P2 } \\
\left(\mu \mathrm{g} \mathrm{m}^{-3}\right)\end{array}$ & $\begin{array}{c}\text { Conc. TSP } \\
\text { in the city } \\
\left(\mu \mathrm{g} \mathrm{m}^{-3}\right)\end{array}$ \\
\hline 1-Jan & 162,2 & 99,6 & 109 \\
1-Feb & 130,1 & 41,3 & 91 \\
1-Mar & 37,2 & 20,3 & 62 \\
1-Apr & 30,8 & 16,3 & 40 \\
1-May & 38,4 & 20,7 & 42 \\
1-Jun & 33,9 & 15,9 & 48 \\
1-Jul & 90,8 & n.a. & 83 \\
1-Aug & 81,1 & 26,1 & 94 \\
1-Sep & 82,3 & 28,4 & 82 \\
1-Oct & 165,8 & 55,2 & 104 \\
1-Nov & 108,6 & 38,3 & 110 \\
14/01 & n.a. & 31,6 & 85 \\
15/01 & 20,7 & 12,2 & 56 \\
16/01 & 19,6 & 9,1 & 35 \\
18/01 & 124,1 & n.a. & 87 \\
21/01 & 155,5 & 108 & 135 \\
22/01 & 172,9 & 50,2 & 105 \\
28/01 & 137,9 & 59 & 139 \\
29/01 & n.a. & 41,9 & 127 \\
30/01 & 137,2 & 40,3 & 145 \\
31/01 & 179,8 & 51,5 & n.a. \\
\hline
\end{tabular}

\section{DISCUSSION}

Data in Table 1 shows that the most critical operations for the formation of airborne materials are in particular excavation, demolition and loading/unloading. With regard to the crushing and screening, the company that operates in the site uses machines that allow minimization of dust generation through nozzles that humidify the material to be treated.
The results of monitoring show that, in general, particulate matter concentrations are lower when:

- The humidity is high

- There is moderate or strong wind and the atmosphere is unstable in the lower layers

- There is weak or no wind and a sunny day

Table 3 and Fig. 4 show that the TSP concentrations in the city are generally higher than the concentrations obtained in P1 (located near the road) and are, in most cases, significantly higher than the measurements made in P2 (site area).

The days in which there is no activity, as well as Saturdays and Sundays, should be considered as moments of persistence of particles in the air due to the continuous presence of deposited mounds and the traffic on the roads next to the measuring points. The contribution of traffic to the airborne concentration in the air, during periods of inactivity, is shown by the high values observed, even after the removal of mounds.

It has been necessary to evaluate the values of $\mathrm{PM}_{10}$ and PM2, 5, in order to better characterize the contribution of the excavation work site from external anthropogenic sources, particularly from urban traffic.

This assessment was achieved by further monitoring campaign next to the receivers and a comparison with the city stations for the measurement of airborne particulates (TSP, $\mathrm{PM}_{10}$ and PM2, 5). 


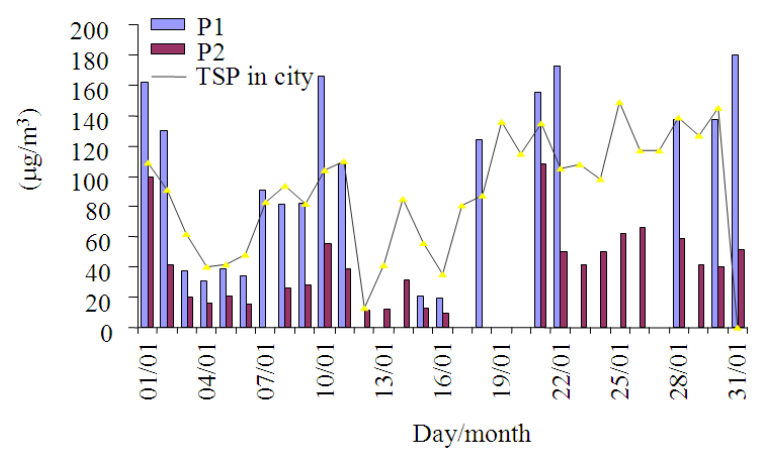

Fig. 4: TSP concentration in $\mathrm{P} 1, \mathrm{P} 2$ and comparison with a monitoring station in the city

The most interesting comparison has been done with data from point $\mathrm{P} 1$, located near the city roads, while the control unit in point $\mathrm{P} 2$ shows very low $\mathrm{PM}_{10}$ concentration, as well as TSP, due to the absence of road in the immediate vicinity of the measuring unit.

The measured values of $\mathrm{PM}_{10}$ in the urban context are strongly influenced by air pollution due to vehicular traffic. In particular, the percentage of $\mathrm{PM}_{10}$ on TSP varies from a low value in August (52.8\%) to a maximum in January (76.1\%). It is possible to read these values as a function of weather and climate and of the external anthropogenic pressures (emissions from vehicular traffic and domestic heating, which varies depending on the season).

$\mathrm{PM}_{10}$ measured in $\mathrm{P} 1$ represented about $70 \%$ of TSP. In the city measurement of $\mathrm{PM}_{10}$ was usually around $10 \%$ higher, confirming the contribution of the excavation work to the particle size greater than 10 microns.

PM2, 5 represent instead $45 \%$ of TSP in point P1, with a lower variability over time than $\mathrm{PM}_{10}$ concentration.

The days of exceedance of TSP concentration of $150 \mu \mathrm{g} \mathrm{m}^{-3}$, often correspond to exceedances of $\mathrm{PM}_{10}$ and PM2, 5 limit values.

It is important to say that the examined excavation work site involved a wide area, respect to the power machine. That means low values of fine particle size, in particular PM2, 5. This is typical of buildings excavation works, respect to infrastructure work, like urban underground excavation works, which present a higher power machine in a reduced area.

It is possible to conclude that excavation work sites in urban areas contribute to increase yet significant particular matter concentration values.

\section{CONCLUSION}

The long-term monitoring next to the receivers showed that the concentration of airborne dust is strongly influenced by:

- The weather and climate (temperature, pressure, relative humidity, wind)

- Type of work activities in the excavation work site (excavation, crushing, screening, demolition, mitigation works)

- Anthropogenic pressures existing in the area near to the site (urban traffic, resurgence of dust caused by transit of working and private vehicles)

It is possible to say that the concentration of TSP is strongly influenced by high values of $\mathrm{PM}_{10}$ and PM2, 5, due in particular to vehicular traffic. The high concentration of total suspended particulate matter, therefore, is not only due to the working activities or to the material deposited for long periods in front of the monitoring unit inside the working site, but also to the existing traffic flow in the near urban area. The significant difference between the particulate matter concentration measured near the road and the values inside the site, but far from roads, are justified by the important contribution of urban traffic flow to the raising of particulate matter concentration. This increase occurs in areas near the urban road network, both on the concentration of $\mathrm{PM}_{10}$ and $\mathrm{PM} 2$, 5, both on TSP, due to the rising of dust deposited on the streets next to the site.

High $\mathrm{PM}_{10}$ and $\mathrm{PM} 2,5$ concentration values involve important health effect on the exposed population, but even when such values are under limit values, an excavation work in urban area can often contribute to increase the disturbance and damage risk.

It can be concluded that an excavation work site located in an urban area contributes to increasing values of the concentration of airborne, which are already high in the air, especially near roads. In order to determine this contribution, to avoid incorrect assessments, it is necessary to monitor TSP values and compare them with the concentration of $\mathrm{PM}_{10}$ and $\mathrm{PM} 2,5$.

\section{REFERENCES}

APHEIS, 2005. Health Impact Assessment of Air Pollution and Communication Strategy. 1st Edn., Institut de Veille Sanitaire, Saint-Maurice Cedex, ISBN: 2110948388, pp: 200. 
AQEG, 2005. Particulate matter in the United Kingdom. 1st Department of the Environment, Food and Rural Affairs, London, pp: 444.

ATS, 2000. What constitutes an adverse health effect of air pollution?. Am. J. Respir. Crit. Care Med., 161: 665-673.

Dockery, D.W., C.A. Pope, X. Xu, J.D. Spengler and J.H. Ware et al., 1993. An association between air pollution and mortality in six U.S. cities. N. Engl. J. Med., 329: 1753-1759. PMID: 8179653

Dockery, D.W., J. Cunningham, A.I. Damokosh, L.M. Neas and J.D. Spengler et al., 1996. Health effects of acid aerosols on North American children: Respiratory symptoms. Environ. Health Perspect., 104: 500-505.

EEA, 1999. Criteria for Euroairnet-the EEA air quality monitoring and information network. European Environment Agency.

EEA, 2007. Air pollution in Europe 1990-2004. European Environment Agency.

EPA, 2005. Review of the National Ambient Air Quality Standards for Particulate Matter: Policy Assessment of Scientific and Technical Information. 2nd Edn., DIANE Publishing, USA., ISBN-10: 1428904697, pp: 530
Hester, R.E. and R.M. Harrison, 1998. Air Pollution and Health. 1st Edn., Royal Society of Chemistry, Cambridge, UK., ISBN-10: 0854042458, pp: 129.

Paoletti, L., B.D. Berardis and M. Diociaiuti, 2002. Physico-chemical characterisation of the inhalable particulate matter $\left(\mathrm{PM}_{10}\right)$ in an urban area: An analysis of the seasonal trend. Sci. Total Environ., 292: 265-275. DOI: $10.1016 /$ S00489697(01)01134-2

Tsai, C.J. and H.Y. Huang, 1995. Atmospheric aerosol sampling by an annular denuder system and a highvolume $\mathrm{PM}_{10}$ sampler. Environ. Int., 21: 283-291. DOI: 10.1016/0160-4120(95)00024-F

WHO, 2003. Health Aspects of Air Pollution with Particulate Matter, Ozone and Nitrogen Dioxide. 1st Edn., World Health Organization, Regional Office for Europe, Copengahen, PP: 94.

WHO, 2006. Air Quality Guidelines: Global Update 2005: Particulate Matter, Ozone, Nitrogen Dioxide and Sulfur Dioxide. 1st Edn., World Health Organization, Denmark, ISBN-10: 9289021926, pp: 484. 